\title{
Reappraisal of risk factors in neoplastic lesions of the cervix uteri
}

\author{
Minakshi Rohilla ${ }^{1 *}$, Hem Prabha Gupta², Anjoo Aggarwal²
}

\begin{abstract}
${ }^{1}$ Department of Obstetrics and Gynecology, PGIMER, Chandigarh 160012, India
${ }^{2}$ Department of Obstetrics and Gynecology, Queen Mary Hospital, King George's Medical university (KGMU), Lucknow, Uttar Pradesh, India
\end{abstract}

Received: 15 March 2017

Accepted: 21 April 2017

\author{
*Correspondence: \\ Dr. Minakshi Rohilla, \\ E-mail: minurohilla@yahoo.com
}

Copyright: (c) the author(s), publisher and licensee Medip Academy. This is an open-access article distributed under the terms of the Creative Commons Attribution Non-Commercial License, which permits unrestricted non-commercial use, distribution, and reproduction in any medium, provided the original work is properly cited.

\begin{abstract}
Background: Carcinoma of uterine cervix is most common cancer amongst women in developing countries and rates the second most common cancer in women throughout the world. Despite possible correlation with factor like age, sexual activity, multiparity, smoking, alcohol, oral contraception and low socio economic status, suggested by various researchers, the exact role and a true causal association between these factors and carcinoma cervix has not been proved as yet.

Methods: Two hundred and fiftyfour (254) patients with cervical lesions were screened for carcinoma of the cervix and 195 were found to be suffering from malignant and intraepithelial lesions. 59 patients had benign lesion of the cervix.

Results: The commonest risk factor encountered in the study was early age at intercourse $(84.25 \%)$ followed by multiparity $(64.56 \%)$, illiteracy $(64.56 \%)$, sexually transmitted disease $(61.02 \%)$, bad hygiene $(43.70 \%)$, low socioeconomic class $(42.91 \%)$, and tobacco use in decreasing order. These factors have complex interrelationship with each other e.g. low socioeconomic status is commonly associated with bad hygiene, illiteracy, multiparity and early age at first intercourse $(\mathrm{p}<0.001)$.

Conclusions: Early detection of benign lesions and decrease in number of risk factors in an individual being minimum at lower age is probably associated with benign part of the spectrum of disease while constant presence of these factors leads to cervical intraepithelial neoplasia followed by truly invasive disease. Intervention at any point with decrease of or absence of risk factors can stop these premalignant lesions to become malignant.
\end{abstract}

Keywords: Carcinoma, Cervix uteri, Epidemiological, Reproductive, Risk factor

\section{INTRODUCTION}

Carcinoma of uterine cervix is most common cancer amongst women in developing countries and rates the second most common cancer in women throughout the world . ${ }^{1}$ The neoplastic lesions of the cervix have attracted the attention of epidemiologist for the many years, as innumerable studies have been conducted looking for the clues to the factors associated with the etiopathogenesis of the disease. ${ }^{1-3}$ There have been interesting changes of age related incidence and other etiological factors associated with cervical neoplasia in the past. Twentieth century epidemiology noted the absence of carcinoma of cervix in a large population of nuns and linked the disease more closely to sexual activity. ${ }^{3}$ Further studies have expanded this observation to emphasize the importance of low socio-economic status, multiparity, early marriages and multiple sexual partners as risk factor for development of carcinoma cervix. $^{4,5}$ Despite possible correlation with possible risk association with age, sexual activity, multiparity, smoking, alcohol, oral contraception and low socio economic status, suggested by various researchers, the exact role and a true causal association between these risk 
factors and carcinoma cervix has not been proved as yet. Comparison of epidemiological and reproductive risk factors for benign, premalignant and malignant cervical lesions in a single study has never been done till date.

In the last few decades, although the screening for cervical cancer has improved, overall incidence has not changed significantly and more women are presenting with late stages of carcinoma cervix due to lack of awareness and knowledge. ${ }^{6,7}$ Present study re-evaluated various epidemiological, sexual and reproductive risk factors in wide spectrum of cervical lesions from benign to premalignant and malignant neoplasm of the cervix in patients attending a north Indian tertiary care hospital.

\section{METHODS}

Two hundred and fifty-four patients of suspected cervical pathology attending the Gynecology Outpatient Department of Queen Mary's Hospital, King George's Medical university Lucknow, India were recruited randomly for evaluation. Patients with clinically looking cervical lesions like erosion, cervical hypertrophy, unhealthy cervix, cervical growth, cervical ulceration or polyp, irrespective of their symptomatology constituted the study design. A detailed history was recorded in each patient with special emphasis to the history of age at first intercourse, number of sexual partners, marital status, obstetric history, menstrual history, history of sexually transmitted disease, use of contraceptive methods, history of tobacco use, alcohol consumption, and personal history like religion, educational qualification, socioeconomic status and personal hygiene. Study was approved by institute ethical committee and informed consent was taken from all the patients at the time of enrolment in to the study.

Patients presenting with obvious cervical growth or polyp were directly subjected to biopsy while patients presenting with erosion, hypertrophy, ulcer underwent cervical cytology followed by colposcopy and colposcopy directed biopsy whenever required. After complete evaluation, the patients were categorised into following groups:

1. Group A: Invasive cervical carcinoma (number of patients-130, cell type squamous cell carcinoma).

2. Group B: Cervical intraepithelial neoplasia (number of patients- 65 , cell type CIN).

3. Group C: Benign cervical pathology (number of patients- 59, chronic cervicitis, cervical erosion, polyp etc.).

For socio-economic assessment Kuppuswamy's scale based on education, occupation and income was applied. ${ }^{8}$ Literacy status was studied as illiterate or literate, the latter including primary as well as higher education, personal hygiene was categorised as criteria laid by Dunn in Indian hygiene and public health. ${ }^{9}$
SPSS 11.5 software (SPSS Inc.; Chicago, IL, USA) was used for statistical analysis. The unpaired t test and the Chi Square test were used as appropriate for the analysis. Fischer's Exact test was also used in place of Chi-square test whenever the number of subjects in any of the cells of the 2 by 2 table was found to be $<5$.

\section{RESULTS}

Demographic data of all patients were as depicted in Table 1 (A and B).

The commonest risk factor encountered in the study was early age at intercourse $(92.12 \%)$ followed by multiparity $(64.56 \%)$, illiteracy $(64.56 \%)$, sexually transmitted disease $(64.56 \%)$, bad hygiene $(43.70 \%)$, low socioeconomic class $(42.91 \%)$, and tobacco use in decreasing order. As majority of sexual partner of women studied $222(87.41 \%)$ were uncircumcised, no conclusion could be established regarding protective role of circumcision for cervical neoplasia. Higher age was preponderant in invasive cervical carcinoma (ICC) as compared to cervical intraepithelial neoplasia (CIN) and benign lesions of the cervix $(\mathrm{P}<0.001)$. Since majority of the patients were Hindus $(88.2 \%)$ no statistically significant correlation was found with religion of either types (P>0.05). ICC occurred more commonly with lower socio-economic status as compared to middle class $(\mathrm{P}<0.001)$ significant association was observed between illiteracy and ICC $(\mathrm{P}<0.001)$. Significant number of patients $75(57.69 \%$ ) had bad hygiene in ICC group. Among the total patients with bad hygiene $67.56 \%$ had ICC $(\mathrm{p}<0.001)$. Tobacco use was more commonly associated with ICC $(65.95 \%)$ as compared to CIN $(18.08 \%)$ and benign lesions of cervix $(15.95 \%)$ Data for alcohol use and dietary status showed no correlation with any lesion type. In patients with ICC $62.5 \%$ were $16-20$ years of age at their first intercourse and $37.5 \%$ were 11 15 years of age. Parity ranged from 0-12. Majority of the patients had parity ranging from 1-6. Parity more than 4 was observed to be commonly associated with ICC 105 (64.02\%) as compared to CIN 31 (18.90\%) and benign lesion of the cervix $28(17.07 \%)$. Although in total only a small percentage of patients used some or the other contraceptive method, the use of non- barrier method of contraception $23(31.50 \%)$ was significantly associated with ICC as compared to use of barrier method of contraception in $2(8.69 \%)$ of patients. Similarly, in CIN use of nonbarrier method of contraception was more commonly observed as compared to barrier method. 155 women $(61.02 \%)$ could recall past history of sexually transmitted disease and a few of them had evidence of sexually transmitted disease at the time of study (Table 2).

Almost all of the patients $99.21 \%$ had only one sexual partner throughout their life. Only two patients $(0.78 \%)$ had two sexual partners by virtue of their second marriage. None of the patients had multiple sexual partners. 
Table 1: (A)- Demographic data of patients (epidemiological) and (B)- Demographic data of patients (reproductive).

\begin{tabular}{|c|c|c|c|}
\hline Total number of patients - 254 & & Number of cases & $\%$ \\
\hline \multirow{3}{*}{ 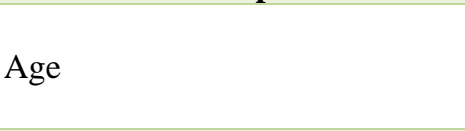 } & a) $20-40 \mathrm{yrs}$ & 99 & 38.46 \\
\hline & a) $41-60 \mathrm{yrs}$ & 138 & 54.84 \\
\hline & a) $61-80$ & 17 & 7.69 \\
\hline \multirow{3}{*}{ SES } & a) upper (class I Kuppuswamy) & 22 & 8.71 \\
\hline & a) middle (class II+III Kuppuswamy) & 123 & 48.71 \\
\hline & a) lower (class IV+V Kuppuswamy) & 109 & 42.56 \\
\hline \multirow{2}{*}{ Religion } & a) Hindu & 224 & 88.20 \\
\hline & a) Muslim & 30 & 11.8 \\
\hline \multirow{2}{*}{ Literacy } & a) Literate & 90 & 35.43 \\
\hline & a) Illiterate & 164 & 64.56 \\
\hline \multirow{3}{*}{ Hygiene } & a) Good & 25 & 9.84 \\
\hline & a) Moderate & 118 & 46.45 \\
\hline & a) $\mathrm{Bad}$ & 111 & 43.70 \\
\hline \multirow{2}{*}{ Dietary habit } & a) Vegetarian & 164 & 64.56 \\
\hline & a) Non-vegetarian & 90 & 35.43 \\
\hline \multirow{2}{*}{ Tobacco use } & a) Present & 94 & 37 \\
\hline & a) Absent & 160 & 63 \\
\hline \multirow{2}{*}{ Alcohol use } & a) Present & 1 & 0.39 \\
\hline & a) Absent & 253 & 99.61 \\
\hline \multicolumn{4}{|c|}{ (B) - Demographic data of patients (reproductive factors) } \\
\hline Total number of patients -254 & & Number of cases & $\%$ \\
\hline \multirow{2}{*}{ Age at first Intercourse } & a) $11-20 \mathrm{yrs}$ & 234 & 92.12 \\
\hline & b) $21-30 \mathrm{yrs}$ & 20 & 7.87 \\
\hline \multirow{4}{*}{ Parity } & a) Nulliparity & 4 & 1.57 \\
\hline & b) $1-3$ & 86 & 33.85 \\
\hline & c) 4-6 & 118 & 46.45 \\
\hline & d) $>6$ & 46 & 18 \\
\hline \multirow{3}{*}{ Contraception } & Barrier & 16 & 6.29 \\
\hline & b) Non barrier & 57 & 22.44 \\
\hline & c) $\mathrm{Nil}$ & 181 & 71.25 \\
\hline \multirow{2}{*}{ STD’s } & a) Past/Present & 155 & 61.02 \\
\hline & b) No evidence & 99 & 38.97 \\
\hline \multirow{2}{*}{ Partner Circumcision } & a) Present & 32 & 12.59 \\
\hline & b) Absent & 222 & 87.40 \\
\hline
\end{tabular}

Yrs-Years, SES-Socioeconomic status, \%-Percentages

STD'S-Sexually transmitted diseases

Table 2: Significance of risk factors in different cervical lesions.

\begin{tabular}{|c|c|c|c|c|c|c|c|}
\hline \multirow{2}{*}{ Risk factors } & \multicolumn{2}{|l|}{$\mathrm{ICC}$} & \multicolumn{2}{|l|}{ CIN } & \multicolumn{2}{|c|}{ Benign Lesions } & \multirow{2}{*}{ Total } \\
\hline & No. of cases & $\%$ & No. of cases & $\%$ & No. of cases & $\%$ & \\
\hline Multiparity $\underline{(>4)}$ & 105 & 64.02 & 31 & 19.90 & 28 & 17.07 & 164 \\
\hline Early age at intercourse $(\leq 20)$ & 130 & 68.37 & 60 & 28.03 & 24 & 11.21 & 214 \\
\hline Illiteracy & 105 & 64.02 & 29 & 17.68 & 30 & 18.29 & 164 \\
\hline Low socioeconomic class & 73 & 66.97 & 20 & 18.34 & 16 & 14.67 & 109 \\
\hline Bad Hygiene & 75 & 67.56 & 23 & 20.72 & 13 & 11.71 & 111 \\
\hline Tobacco use & 62 & 65.95 & 17 & 18.08 & 15 & 15.95 & 94 \\
\hline Sexually transmitted disease & 55 & 35.48 & 50 & 32.25 & 50 & 32.25 & 155 \\
\hline
\end{tabular}

$\mathrm{X} 2($ chi-square $)=78.838(\mathrm{P}$ value $<0.001)$

Prevalence of all risk factors in respective cervical lesion was highly significant.

ICC-invasive cervical carcinoma, CIN-Cervical intraepithelial neoplasia 
Table 3: Comparison of risk factors in different groups of cervical lesions.

\begin{tabular}{|lllllll|}
\hline Risk factors & A versus B & \multicolumn{2}{c|}{ A versus } & \multicolumn{3}{l|}{ B versus C } \\
\hline & $\mathbf{Z}$ & $\mathbf{P}$ & $\mathbf{Z}$ & $\mathbf{P}$ & $\mathbf{Z}$ & $\mathbf{P}$ \\
\hline Multiparity $(\geq 4)$ & 8.2937 & $<0.001$ & 8.6593 & $<0.001$ & 0.4312 & $>0.05$ \\
\hline Early age at intercourse $(\leq 20$ Year) & 9.2915 & $<0.001$ & 13.9645 & $<0.001$ & 5.8279 & $<0.001$ \\
\hline Illiteracy & 8.5368 & $<0.001$ & 8.4149 & $<0.001$ & 0.4137 & $>0.05$ \\
\hline Low socioeconomic class & 7.2578 & $<0.001$ & 7.8544 & $<0.001$ & 0.7296 & $>0.05$ \\
\hline Bad Hygiene & 6.6491 & $<0.001$ & 6.9706 & $<0.001$ & 0.3813 & $>0.05$ \\
\hline Tobacco use & 7.0284 & $<0.001$ & 8.5096 & $<0.001$ & 1.8208 & $>0.05$ \\
\hline Sexually transmitted disease & 0.600 & $>0.05$ & 0.600 & $>0.05$ & 0.600 & $>0.05$ \\
\hline
\end{tabular}

Group A = ICC, Group B = CIN, Group C = Benign lesion

ICC-invasive cervical carcinoma, CIN-Cervical intraepithelial neoplasia

$\mathrm{Z}=\mathrm{Z}$ score, $\mathrm{P}=\mathrm{P}$ value

On analysing interrelationship prevalence of all risk factors are significantly higher in Group A (ICC) than B $(\mathrm{CIN})(\mathrm{p}<0.001)$ and $\mathrm{C}($ Benign $)(\mathrm{p}<0.01)$ except sexually transmitted disease, those have equal association with all types of cervical lesion ( $p>0.05$ ). Prevalence of early intercourse are significantly higher in Group B than C $(\mathrm{p}<0.001)$, regarding other factors in Group B than C, difference is insignificant ( $p>0.05)$.

Prevalence of all risk factors in invasive cancer and intraepithelial neoplasia are significantly higher than in benign lesions of the cervix $(\mathrm{p}<0.001)$. There is significant association between the concomitant presence of early age at intercourse and multiparity $(\mathrm{p}<0.001)$ in ICC and CIN and that is possibly because of earlier sexual exposure and ignorance and taboos regarding use of contraceptive method (Table 3).

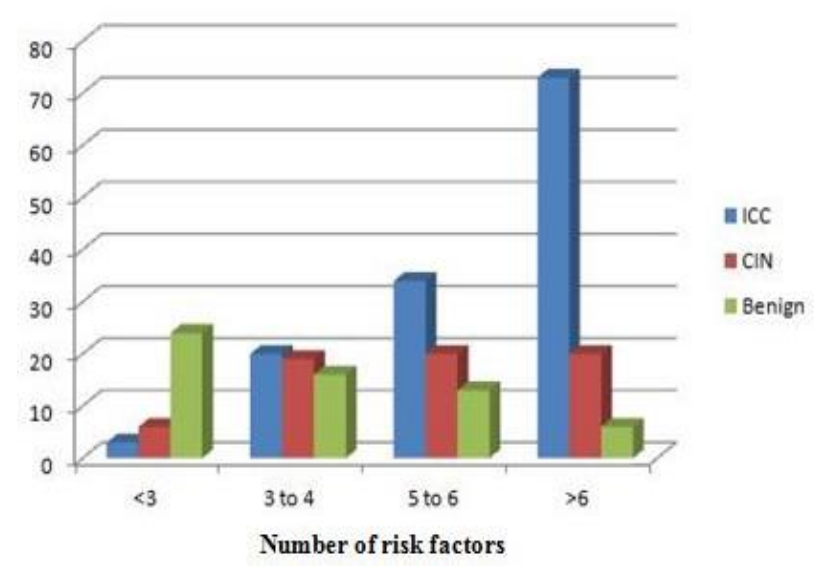

Figure 1: Correlation of cervical lesions and number of risk factors.

It is evident that majority of patients of cervical neoplasias $166(65.35 \%)$ had more than 5 risk factors for the disease, while only $33(12.99 \%)$ patients had less than 3 risk factors for cervical neoplasias. Majority of patients having more than 6 risk factors for the disease were belonging to frankly invasive and cervical intraepithelial neoplasia (93.93\%) (Figure 1).

\section{DISCUSSION}

The changing trends of age incidence of carcinoma of cervix with more patients commonly affected in 31.9 \pm 9.77 (Min: 15.00-Max: 49.00) 25-40 years of age has been shown by Sogukpinar $\mathrm{N}$ et al. ${ }^{10}$ Although age range among patients with ICC remained between 20-80 years but mean age $(35.86 \pm 3.45)$ reflects younger women to be equally affected. It is well known that invasive carcinoma occurs more commonly in higher age group but the present study shows that younger women i.e. 3040 are equally affected. This may be possibly because of trends of early marriage in our society leading to early age at first intercourse, exposure to sexually transmitted pathogens and tobacco use. As reported by others age trends in present study also showed a decreasing age as one moves from frankly invasive disease ICC to benign lesions of cervix through CIN (P value $<0.001) .{ }^{1}$ Although average literacy rate of the population to which patients belonged is to the extent of $40 \%$ but illiteracy was significantly associated with ICC in our patients as previously reported ( $\mathrm{P}$ value $<0.001)$ (4-5). This is probably because of poor sexual hygiene and ignorance about disease in illiterate class of patients. Present data confirms the association of bad hygiene with cancer cervix as observed by Raychaudhuri S and Mandal S. ${ }^{11,12}$ Trends in socio-economic status as studied previously are difficult to interpret due to many variables in assessment of socio economic status. Lower to middle socio economic status has been shown to be associated with cervical cancer by others as in present study. ${ }^{12}$ Role of smoking and use of tobacco in other forms has been shown by various investigators' as a risk factor for carcinoma cervix..$^{13}$ Similar trends have been observed in our data. No correlations could be made between cervical neoplasia and religion and dietary status due to statistically insignificant data in present study. Similarly alcohol use was also not found in patients studied. It seems that due to conservative nature of our society, patients were not forthcoming with history of alcohol use 
although many of them may have been using it. The present study points further towards changing age trends of carcinoma cervix and identifies the previously described risk factors. Early age at first intercourse was significantly lower $(\mathrm{P}<001)$ in majority of the patients studied, probably because of trends of early marriage in our society. Lower age at intercourse has been regarded as risk factors by Wong HY et al and others. ${ }^{5,11,12}$ Our result are consistent with previous studies and with the study of Indian population by Biswas et al which showed more risk of carcinoma cervix with age at fist intercourse less than 12 years. ${ }^{14}$ In the present study, increasing parity was found to be commonly associated with ICC than CIN. Makuza et al have shown increased risk of carcinoma cervix proportionally with increase in parity. ${ }^{15}$ Although not statistically significant $(p>0.05)$ none of the nulliparous patient developed carcinoma cervix. Parity more than 10 was only observed with ICC as compared to other lesion, which clearly demonstrated that high parity is related to cervical carcinoma $(\mathrm{p}<0.001)$. Majority of patients had a single sexual partner $(99.22 \%)$ which seems at variance with expected increase in number of sexual partners in patients with cervical carcinoma as shown by previous studies. ${ }^{16,17}$ It seems that due to conservative sexual habit of our population and sex with more than one being regarded as taboo, our patients were not revealing their sexual history thoroughly. In our study 183 patients were at risk for cervical neoplasia as they were either using non barrier method of contraception or not using any method of contraception. In carcinoma cervix majority of patients used non barrier method of contraception, which has been shown to become commonly associated with invasive cell carcinoma of cervix. ${ }^{11}$ High prevalence of high grade lesions in women affected with trichomonas vaginalis and genital warts as suggested by Lixin Tao, $61 \%$ of the studied women had previous or present evidence of sexually transmitted diseases. ${ }^{1}$ Due to paucity of data regarding number of sexual partners and circumcision in the partner, these could not be ascertained as significant risk factor as suggested by previous studies. The current study has revealed that the prevalence of risk factors in studied population was very high. It was obvious form the study that factors like early age at first intercourse, multiparity, poor hygiene, illiteracy, etc. were more commonly present with the invasive carcinoma than intraepithelial neoplasia and benign lesion of the cervix. These factors have complex interrelationship with each other e.g. low socioeconomic status is commonly associated with bad hygiene, illiteracy, multiparty and early age at first intercourse. It seems that neoplastic disease of the cervix has a spectral distribution with clearly demonstrable invasive cervical carcinoma at one end and benign inflammatory disease (chronic cervicites / cervical erosion) at the other end; cervical intraepithelial neoplasias are occupying the middle part of the spectrum. Although it may seem to be over simplification of the subject but it looks that a younger woman is amenable to inflammatory lesions of the cervix which if left unattended especially in presence of continuous presence of risk factors develop chronic inflammatory changes followed by intraepithelial neoplasia and invasive carcinoma in due course of time. Early detection of benign lesions and decrease in number of risk factors in an individual being minimum at lower age is probably associated with benign part of the spectrum of disease while constant presence of these factors leads to cervical intraepithelial neoplasia followed by truly invasive disease. Intervention at any point with decrease of or absence of risk factors can stop these premalignant lesions to become malignant. There is a limitation to this study; detection of HPV infection could not be done in all women because of financial constraint, however evidence of STD was there in the form of history, examination and cytopathology of the cervix.

Present study re-emphasizes importance of cervical screening services for early diagnosis and intervention in all women and especially in those where one or more of these risk factors are co-existent. More emphasis should be laid to impart health education to all women regarding risk factors for carcinoma of cervix.

\section{Funding: No funding sources \\ Conflict of interest: None declared \\ Ethical approval: Not required}

\section{REFERENCES}

1. Tao L, Han L, Lil X, Gao Q, Pan L, Wu L et al. Prevalence and risk factors for cervical neoplasia: a cervical cancer screening program in Beijing. BMC Public Health. 2014;14:1185.

2. Murthy NS, Mathew A. Risk factors for Precancerous lesions of the cervix. European Journal of Cancer Prevention. 2000;9:5-14.

3. Fregaa A, Stentellaa P, Andrea De I, Piazzea JJ, Fambrinib M, Marchionnib M, et al. Young women, cervical intraepithelial neoplasia and human papillomavirus: risk factors for persistence and recurrence. Cancer Letters. 2003;196:127-34.

4. Thulaseedharan JV, Malila N, Hakama M, Esmy PO, Cheriyan M, Swaminathan R, et al. Socio demographic and reproductive risk factors for cervical cancer-a large prospective cohort study from rural India. Asian Pac J Cancer Prev. 2012;13(6):2991-5.

5. Wong HY, Loke AY, Chan NH. Risk factors for cervical abnormalities among Hong Kong Chinese women: a large-scale community-based cervical screening program. J Womens Health. 2011;20(1):53-9.

6. Tadesse SK. Preventive Mechanisms and Treatment of Cervical Cancer in Ethiopia. Cervical Cancer. 2015;1:101.

7. Abate SM. Trends of Cervical Cancer in Ethiopia. Cervical Cancer. 2015;1:103.

8. Kuppuswamy B. Manual of socio-economic status scale (urban) Maaanasayan, 32, Neta J Subhash Marg Delhi-6; 1976. 
9. Dunn CL, Pandya DD. Personal hygiene. In: Indian hygiene and public health, Butterwarld and Co. Calcutta; 1925:282-293.

10. Sogukpinar N, Saydam BK, Can HO, Hadimli A, Bozkurt OD, Yucel U, et al. Assessment of cervical cancer risk in women between 15 and 49 years of age: case of Izmir. Asian Pac J Cancer Prev. 2013;14(3):2119-25.

11. Raychaudhuri S, Mandal S. Socio-demographic and behavioural risk factors for cervical cancer and knowledge, attitude and practice in rural and urban areas of North Bengal, India. Asian Pac J Cancer Prev. 2012;13(4):1093-6.

12. Raychaudhuri S, Mandal S. Current status of knowledge, attitude and practice (KAP) and screening for cervical cancer in countries at different levels of development. Asian Pac J Cancer Prev. 2012;13(9):4221-7.

13. Trimble CL, Genkinger JM, Burke AE, Hoffman SC, Helzlsouer KJ, Diener-West M, et al. Active and Passive Cigarette Smoking and the Risk of Cervical Neoplasia Obstet Gynecol. 2005;105(1):174-81.
14. Biswas LN, Manna B, Maiti PK, Sengupta S. sexual risk factors for cervical cancer among rural Indian women. Int J Epidemiol. 1997;26:491-5.

15. Makuza JD, Nsanzimana S, Muhimpundu MA, Pace LE, Ntaganira J, Riedel DJ. Prevalence and risk factors for cervical cancer and pre-cancerous lesions in Rwanda. The Pan African Medical Journal. 2015;22(1).

16. Reid J. Women's knowledge of Pap smears risk factors for cervical cancer. J Obstet Gynecol Neonatal Nurs. 2001;30(3):299-305.

17. Almonte M, Albero G, Molano M, Carcamo C, García PJ, Pérez G. Risk factors for Human Papillomavirus Exposure and Co-factors for Cervical Cancer in Latin America and the Caribbean. Vaccine. 2008;26(11): L16-36.

Cite this article as: Rohilla M, Gupta HP, Aggarwal A. Reappraisal of risk factors in neoplastic lesions of the cervix uteri. Int J Reprod Contracept Obstet Gynecol 2017;6:2381-6. 